\title{
RELATIONSHIP BETWEEN PARENTING STYLE AND ADOLESCENTS' ALCOHOL CONSUMPTION IN ENUGU STATE, NIGERIA: IMPLICATIONS FOR COUNSELLING
}

\author{
C. Obioma Ezeh ${ }^{\mathrm{a} *}$ \\ ${ }^{a}$ Depth of Educational Psychology, Federal College of Education,Eha Amufu,Enugu State, Nigeria
}

\begin{abstract}
The crime rate in Nigeria, especially in states within the South-East zone, is very high and most of these crimes and anti-social behaviours were carried out by adolescents or youths. Many Nigerian adolescents indulge in such anti-social behaviour and crimes under the influence of alcohol. A person's behaviour is the resultant effect of a combination of factors and as such the behaviour of Nigerian adolescents that engage in alcohol consumption with reckless abandon calls to question the parental influence on their children's behaviour. One is then bound to wonder if this problem of alcohol indulgence originates from the kind of parenting in their various homes. The purpose of this paper was therefore to find out if the parenting style adopted in families can be linked with the youths' drinking habits with a view to directing counselling services to their homes. This was a survey research with a sample of 1200 adolescents, drawn from senior secondary classes and tertiary institutions in Enugu State of Nigeria. The instrument for the study was questionnaire, designed by the researcher. Two research questions were answered while one hypothesis was tested using a chi square. It was found that adolescents from authoritarian and authoritative families had less inclination to alcohol consumption as against those from permissive and indifferent families. It was also found that adolescents in urban cities take to alcohol more than those in rural areas. It was therefore, concluded that the parenting style adopted in families has significant relationship with the children's alcohol consumption.
\end{abstract}

Keywords: Adolescent, parenting styles, counslling and alcohol

(C) 2012 Published by C-cres. Peer-review under responsibility of Editor(s) or Guest Editor(s) of the EJSBS.

${ }^{*}$ Corresponding author.

E-mail address: docobyezeh@gmail.com; clareoby@yahoo.com 
https://doi.org/10.15405/FutureAcademy/ejsbs(2301-2218).2012.3.14

eISSN: 2301-2218 / Corresponding Author: C. Obioma Ezeh

Selection \& Peer-review under responsibility of the Editors

\section{Introduction}

Human development and behaviour are resultant effect of a number of factors working in isolation or in combination with the family playing prominent role. Developmental psychologists have been interested in identifying how parents impact on their children's development, with the aim of finding any cause-and-effect links between specific actions of parents and later behaviour of children (Cherry, 2012).

It is a well known fact that the family is the first agent of socialization for every child and in developing countries like Nigeria, the family continues to exert much influence on a person's development and behaviour all through one's life time. According to Omede and Odiba (2008) as well as Chiejina (2008), the home environment, especially the parents as pivot upon which home issues revolve, is a very critical factor in shaping the behaviour of children, emotionally, socially and academically. This even becomes more imperative during the adolescence years, during which an individual's personal identity is formed.

Adolescence here refers to the period of development between childhood and adulthood, which is characterized by a number of physiological and psychological changes. In Nigeria, adolescence corresponds to the secondary school and university/college years. Adolescents' behaviour is influenced by a number of environmental happenings around them, which often push them into experimentation and one of such factors is parenting style adopted in families.

\subsection{Parenting Style Defined}

Parenting is a complex activity that includes many specific actions of the parents that work individually and collectively to influence a child's behaviour and expectation. It is that specific parent's behaviors, which may influence a child's development in one way or the other. The construct of parenting style is used to capture normal variations in parents' attempts to control and socialize their children (Baumrind, 1991), with two critical points: - normal variations in parenting and control. She put forward four basic elements that could help shape successful parenting as: responsiveness versus unresponsiveness and demanding versus undemanding. Even as parents may differ in how they try to control or socialize their children and the extent to which they do so, it is assumed that the primary role of all parents is to influence, teach, and control their children. Thus, parenting style captures two important elements of parenting: parental responsiveness and parental demandingness (Maccoby \& Martin, 1983). 
https://doi.org/10.15405/FutureAcademy/ejsbs(2301-2218).2012.3.14

eISSN: 2301-2218 / Corresponding Author: C. Obioma Ezeh

Selection \& Peer-review under responsibility of the Editors

Parental responsiveness (which is parental warmth or supportiveness) refers to the extent to which parents intentionally foster individuality, self-regulation, and self-assertion by being attuned, supportive, and acquiescent to children's special needs and demands, (Baumrind, 1991). Parental demandingness (which is behavioural control), on the other hand, refers to the claims parents make on children to become integrated into the family whole, by their maturity demands, supervision, disciplinary efforts and willingness to confront the child who disobeys (Baumrind, 1991).

From the four basic elements that could shape successful parenting, Baumrind identified three general parenting styles as: - authoritative, authoritarian, and permissive. However, Maccoby and Martin expanded the styles to four by including indifferent or neglectful style. Thus, the four common parenting styles are: - authoritarian, authoritative, indulgent and indifferent. These four styles of parenting involve combinations of acceptance and responsiveness on the one hand and demand and control on the other.

The authoritarian style also known as autocratic style refers to a situation whereby parents place much demands on the children without establishing a reciprocal relationship. Such parents are very strict with the children dishing out orders and rules to be followed without questioning. The authoritative style also known as democratic style is the type in which children are allowed to participate in family discussion in issues concerning them. The permissive style also known as indulgent style refers to a situation whereby children are given full freedom to do whatever they like without restriction or punishment from parents. The fourth style which is indifferent or neglectful style is a rare type of parenting. Here, parents do not show any interest in their children's activities or whereabouts.

\section{Problem Statement}

There is a high rate of crimes and anti-social behaviour in Nigeria, especially in states in the South-East Zone (Ogara, 2012). Adolescents were usually at the centre of such crimes and anti-social behaviours and the crimes were committed under the influence of alcohol and hard drugs. Observation has shown that alcohol consumption is common among adolescents in secondary schools and tertiary institutions in the south-eastern part of the country.

This worrisome situation prompted this researcher to wonder if such practice has any link with the type of parenting they received in their homes, which exposes and encourages the young members of the family to indulge in alcohol consumption. For Mgboro (2008) has opined that parents have the primacy of place in the process of children interacting with the environment as they grow up. It was Diana Baumrind that first put up argument on the 
https://doi.org/10.15405/FutureAcademy/ejsbs(2301-2218).2012.3.14

eISSN: 2301-2218 / Corresponding Author: C. Obioma Ezeh

Selection \& Peer-review under responsibility of the Editors

connection between the parental behavior and the development of instrumental competence, which refers to the ability to manipulate the environment to achieve one's goals.

However, Harris (1998) has argued that different forms of parenting do not have significant effects on children's development, short of cases of severe abuse or neglect. She insisted that the purported effects of different forms of parenting are all illusions caused by heredity, the culture at large, and children's own influence on how their parents treat them. All the same, this researcher felt a lot of concern for increased alcohol- induced crimes in this region and therefore sought to seek if there is any link between the parenting styles in various families and their adolescents' drinking habit.

\section{Research Questions}

1. To what extent does the style of parenting contribute to adolescents' intake of alcoholic drinks?

2. How does the residential area of adolescents relate with their drinking habit?

\subsection{Hypothesis}

Ho: There is no significant difference in the rate of alcohol consumption by adolescents in urban centres and those in rural areas.

\section{Purpose of the Study}

This study was necessitated because of the increasing rate of alcohol-induced crimes in South-East Zone of Nigeria, which has Enugu State as the centre. The purpose of this paper specifically was to find out if the parenting style adopted in families can be linked with the youths' drinking habits with a view to directing counselling services to their homes. Two research questions guided the study while one hypothesis was tested.

\section{Research Methods}

The study was carried out in Enugu State, which is the centre of the five states that make up the South-East Zone of Nigeria. Enugu State has seventeen local government areas grouped into six education zones. A sample of one thousand, two hundred (1200) adolescent students (from Senior Secondary classes and College/University) was randomly selected from all the education zones. 100 students were randomly selected from each of the two universities and a College of Education within the State. Two schools (one from the rural area and one 
https://doi.org/10.15405/FutureAcademy/ejsbs(2301-2218).2012.3.14

eISSN: 2301-2218 / Corresponding Author: C. Obioma Ezeh

Selection \& Peer-review under responsibility of the Editors

from the urban/semi-urban centre) were randomly chosen from each zone and seventy five (75) students randomly selected from each of the sampled schools.

The instrument used for the study was a 10-item questionnaire designed by the researcher to elicit information on the family interaction between parents and their children and respondents' involvement in alcohol consumption. The questionnaire was a four-point Likert scale of: - Strongly Agree (SA); Agree (A); Disagree (D) and Strongly Disagree (SD). The first section sought for information about the age and residential area of the respondents. The data was analyzed using frequency tables and mean scores as well as Chi square test. The weighting for the Likert scale was: - SA - 4 points; A - 3 points; D -2 points and SD - 1 point. A mean score of 2.5 was taken as the base line so that those with mean score above 2.5 were taken to indicate positive and high relation, while those with mean score below 2.5 were taken to have little relation.

\section{Findings}

In order to answer the research question 1, the responses on their freedom to take alcohol were juxtaposed with their responses on parent-children interaction at home and presented as in table 1:

Table 1. Parenting Style and adolescents' Freedom to drink alcohol

\begin{tabular}{cllllll}
\hline Parenting Style & Sa & A & D & Sd & Total & Mean \\
\hline Authoritarian & 14 & 29 & 37 & 58 & 138 & 1.99 \\
Authoritative & 43 & 70 & 158 & 174 & 445 & 1.96 \\
Permissive & 138 & 175 & 73 & 41 & 427 & 2.96 \\
Indifferent & 56 & 93 & 25 & 16 & 190 & 3.00 \\
Total & 251 & 367 & 293 & 289 & 1200 & \\
\hline
\end{tabular}

In the above table, it was found that adolescents from authoritarian and authoritative parents had less inclination to drinking alcohol with their mean scores of 1.99 and 1.96 respectively. On the other hand, adolescents from permissive and indifferent parents exhibited greater freedom to drinking alcohol with their mean scores of 2.96 and 3.00 respectively.

When these figures were subjected to chi- square test at 0.05 level of significance, the calculated chi square value was 298.71 .

This was far higher than the table chi square value of 16.92 at 0.05 level of confidence 
https://doi.org/10.15405/FutureAcademy/ejsbs(2301-2218).2012.3.14

eISSN: 2301-2218 / Corresponding Author: C. Obioma Ezeh

Selection \& Peer-review under responsibility of the Editors

at 9 degrees of freedom. This showed that there was close relationship between the parenting style and adolescents' consumption of alcohol.

To answer the research question 2, their responses to their drinking habits were juxtaposed with the responses on residential area and presented as shown in table 2.

Table 2. Residential Area and Adolescents' Drinking Habits

\begin{tabular}{llllll}
\hline Residential Area & Yes & $\%$ & No & $\%$ & Total \\
\hline Rural Areas & 254 & 21 & 328 & 27 & 582 \\
Urban Centres & 478 & 40 & 140 & 12 & 618 \\
Total & 732 & & 468 & & 1200 \\
\hline
\end{tabular}

From the table, it was found that almost $40 \%$ of the respondents, who were urban dwellers, admitted that they drink alcohol as against about $21 \%$ who were rural dwellers. Again, a higher number of rural dwellers (about 27\%) had never tasted alcohol as against a smaller proportion $(11 \%)$ who were urban dwellers.

In testing the hypothesis on possible difference in drinking habits due to residential areas, their responses were subjected to the Chi square test at 0.05 level of significance, the calculated $(\chi 2)$ value was 143.12 while the table value at 1 degree of freedom at 0.05 level of confidence was 3.841. Since the calculated chi square value was greater than the table value, it then followed that the null hypothesis was rejected. This meant that there was a significant difference in the alcohol drinking habit of adolescents in rural areas and urban centres.

\subsection{Discussion}

From the findings it was seen that the way parents handle their children contribute to their drinking habits since adolescents from different family styles showed variations in their drinking habits. This agrees with the views of Langfield, Maclntye, and Turner (2011), who said that one of the strongest factors that influence alcohol and substance abuse is the family interaction. Similarly, Chandrasheka (2007) has reported that substance use are often linked with a number of factors including the behaviour and attitudes of significant others like parents and older siblings. Similarly, the Wikipedia encyclopedia cited a recent study report which showed that

- The teens least prone to heavy drinking had parents who scored high on both accountability and warmth.

- So-called 'indulgent' parents, those low on accountability and high on warmth, 
https://doi.org/10.15405/FutureAcademy/ejsbs(2301-2218).2012.3.14

eISSN: 2301-2218 / Corresponding Author: C. Obioma Ezeh

Selection \& Peer-review under responsibility of the Editors

nearly tripled the risk of their teen participating in heavy drinking.

- 'Strict parents' - high on accountability and low on warmth - more than doubled their teen's risk of heavy drinking.

- It went further to say that children of permissive parents may tend to be more impulsive, and as adolescents, may engage more in misconduct, and in drug use.

The authoritarian parents who are very strict with the young ones produce adolescents who are less prone to alcohol consumption, unlike the indifferent parents who do not care about what their children do. This could have arisen from fear of being punished by their parents if found drinking and not that they were aware of the health hazards associated with alcohol consumption. But it is not enough to be strict in discipline without explaining to the young ones the implication of their behaviour. Adolescents from authoritative parents admitted that they had been advised by their parents on the dangers and health implications of alcohol but they were not restricted from taking it.

\subsection{Implications for Counselling}

Adolescence is usually characterized by experimentation - during which the young ones try to experiment on varieties of life styles including the use of drugs and alcohol. In view of this, it is a period when parents should be very careful and tactical in handling them by explaining the reasons for their restrictions and other societal issues. Communication gap is a serious hindrance in children upbringing as many people had entered one form of problem or the other due to lack of proper information, especially from their parents.

According to Guzman (2011), while it seems that teens are influenced by their peers, parents continue to be the most influential factor in their lives. She then cautioned parents to create and maintain constant communication with their teen children no matter the situation. As such Parents should be made to realize that with a good foundation at home, many adolescents hardly depart from the standard already set in the family, including use of drug and alcohol.

\section{Conclusions}

From the findings which showed that adolescents from authoritarian and authoritative families had less inclination to alcohol consumption as against those from permissive and indifferent families; and that adolescents in urban cities take to alcohol more than those in rural areas; It can therefore, be concluded that the parenting style adopted in families has significant relationship with the children's alcohol consumption. 
https://doi.org/10.15405/FutureAcademy/ejsbs(2301-2218).2012.3.14

eISSN: 2301-2218 / Corresponding Author: C. Obioma Ezeh

Selection \& Peer-review under responsibility of the Editors

\subsection{Recommendations}

Based on the findings from this study, the writer wishes to make the following recommendations: -

- Government should introduce and sustain parent education programmes to enlighten parents on good child-rearing styles.

- School Counsellors should always enlighten their students on the health hazards and dangers associated with alcohol consumption, because as the saying goes - "to be fore-warned is to be fore-armed.

- School Counsellors should also make effort to get to know the parents of their students and try to provide them with useful tips on how to handle their children at home.

\section{Acknowledgements}

The authors declare that there is no conflict of interest.

\section{References}

Baumrind, D. (1991). The Influence of Parenting Styles on Adolescent Competence and Substance Use. The Journal of Early Adolescence, 11(1), 56-95.

Cherry, K. (2012). Parenting Styles: The Four Styles of Parenting. Retrieved from http://psychology.about.com/od/developmentalpsychology/a/parenting-style.html

Chiejina, E. N. (2008). Family Correlates of Low and High Achieving Adolescent Students. The Educational Psychologist, 4(1), 139-145

Guzman, M. R. T. (2007). Friendships, Peer Influence and Peer Pressure during the Teen Years.

Harris, J. R. (1998). The Nurture Assumption: Why Children Turn out the Way They Do. Adopted from the Parenting Styles. Retrieved from http://en.wikipedia.org/ w/index.php?title=Parenting_styles\&oldid=474542504

Langfield, P. A., Maclntyre M., Turner J. G., \& Fetsch, R. J. (2004). Adolescent Alcohol and Drug Abuse. Retrieved from https://mountainscholar.org/bitstream/handle/ 10217/196544/AEXT_ucsu20622102162004.pdf?sequence=1\&isAllowed=y

Maccoby, E. E., \& Martin, J. A. (1983). Socialization in the Context of the Family: ParentChild Interaction. In P. H. Mussen, \& E. M. Hetherington (Eds.), Handbook of Child Psychology: Vol. 4. Socialization, Personality, and Social Development (pp. 1-101). 
https://doi.org/10.15405/FutureAcademy/ejsbs(2301-2218).2012.3.14

eISSN: 2301-2218 / Corresponding Author: C. Obioma Ezeh

Selection \& Peer-review under responsibility of the Editors

New York, NY: Wiley.

Mgboro, C. U. (2008). Perceived Parental Acceptance as Correlate of Creativity Among Primary School Pupils in Ebonyi State. Journal of the Nigerian Academy of Education. 4(1), 146-159.

Chandrasheka, C. R. (Ed) (2007). National Institute of Mental Health and NeuroSciences (2007). Manual of Students' Counselling for College Teachers. India, Bangalore 506029.

Ogara, I. (2012). Stakeholders Fight Against Alcohol and Smoking Hemp in Ohom. The Starlite Newspaper. Retrieved on May 7, 2012, from https://thestarlite.wordpress.com

Omede, J., \& Odiba, P. (2008). Comparative Analysis of the Role of Parents in Monitoring Learning Behaviours of Primary School Children. The Educational Psychologist, 4(1), 116-124.

Wikipedia. (2012). Retrieved on May 17, 2011 from http://en.wikipedia.org/w/index. php?title=Parenting_styles\&oldid=474542504 